\title{
The Growing Global Demand for Element Gallium: Electrical and Electronic Waste and Coal Fly Ash as Alternative Sources for its Sustainable Supply
}

\author{
Hezron T. Mwakabona \\ ${ }^{1}$ Department of Physical Sciences, Sokoine University of Agriculture, P.O. Box 3038, Morogoro, Tanzania
}

\begin{abstract}
Gallium (Ga) is listed among the critical elements because of its high demand, low crustal concentration and dispersed occurrence. Growth in demand for this element is a response to proliferation in production of electronic devices and a global effort to decarbonised power production. This situation calls for exploitation of alternative sources such as fly ash and recycling processes from finished products. Wide implementation of these options is yet to be witnessed or still in their infancy with only a few facilities worldwide. This is attributable to low material intensity per unit product and the fact that this kind of waste has not accum ulated high enough to attract recycling for instance. Most gallium bearing devices though have other critical, precious and or non-precious elements that co-exist with it. These co-existing elements are relatively high in concentrations and some of them are already being recycled from the same end-of-life products. Therefore an option that involves co-recovery of gallium together with other co-existing elements which are already being recycled and extraction from other sources such as fly ash is to be a viable pursuit in sustaining gallium supply. Viability stems on the similarities of gallium concentration in those sources, recovery methods and conditions used in recycling of gallium. More research however, to explore potential combinations of co-existing metals to be co-extracted with and methods to be employed is vital.
\end{abstract}

Keywords: Photovoltaic, end-of-life products, light-emitting diode (LED), companion element, critical element

\section{Introduction}

Gallium is listed among the critical elements together with germanium indium, tellurium and selenium $[1,2]$ because of its high demand, low crustal concentration and dispersed occurrence [3] Increase in population, rise of life standard and a wave of life style change driven by economic growth in different nations add up to criticality of this element [4]. Lovik et al. [3] (and ref. cited therein) showed that gallium production increased from 292 to 383 metric tonnes from 2012 to 2013 [5] and that gallium production is now four times higher than it was before 2010. Annual gallium production currently is beyond $400 \mathrm{t}$ [6]. Demand for gallium is forecasted to increase up to $224 \%$ by 2050 compared to 2010 [7]. This implies that the market share of this element increases and will continue to increase steadily with time. Interestingly, in 2011 demand for element gallium exceeded that year's production by $86 \mathrm{t}$ wh ich was obtained from the stockpile [7]. This is an indication that production capacity was beyond the real world demand in that year. Some of the notable areas where gallium demand has significantly increased are power production and electronics as hereunder presented.

Global warming among other environmental challenges has redirected governments to reduction in use of energy sources that produce greenhouse gases [8]. Solar and wind power stand out as best alternatives for sustainable green power supply. Energy extractable from the sun is in the order of terawatt, more than enough power for the whole globe. At the core of solar energy is the photovoltaic technology that uses elements such as gallium and silicon in thin film and crystalline photovoltaic (PV) cells respectively [3]. In thin film PV cells, gallium is used together with other metals such as copper, indium, and selenium in the form of Copper-
Indium-Gallium-diSelenide (CIGS) $\quad[3,7,9] . \quad$ Typical concentration of gallium in CIGS rages between 2.3 and 19.7 $\mathrm{kg}$ per mega-watt of power or $0.53 \mathrm{~g} / \mathrm{m} 3$ of the unit $[6,10]$. Therefore, the more governments shift to green sources of power the more the demand for these elements. In 2010, the market share of silicon-based photovoltaics was $90 \%$ and that of gallium-based only $10 \%$ [10]. However, the market share of gallium-based photovoltaic cells increased from $10 \%$ in 2010 to $25 \%$ in 2012 [9]. No wonder then that, projections indicate a decreased silicon share in the photovoltaic production to $20 \%$ by 2050 [11]. This can be attributed to the higher efficiency of gallium based devices than silicon based devices [8]. Besides, photovoltaics production in attempts to decarbonise power production, LED dependent energy efficient lights need gallium in their production [4]. Angerer et al. (2009) cited in Bleischwitz [4] estimate the demand for photovoltaic cells and LED to increase over the current total world production by a factor of six by 2030 . Thus as the gallium share in the photovoltaic devices increases so will its demand do which eventually will command increase in its supply [11].

Apart from photovoltaic production, gallium has a wide application in electronic devices [4] such as GaAS and GaN based integrated circuits. In 2011, distribution of these applications was such that integrated circuits $(\mathrm{GaAs})$ consumed $267.6 \mathrm{t}$ and laser diode and LED displays (GaN) combined consumed $101.7 \mathrm{t}$ of the total gallium produced in that year, which was approximated at $378 \mathrm{t}$ [7]. The remaining was used in photodetectors production $(\mathrm{GaN}) 5.4 \mathrm{t}$ and solar cells and research and development combined which used the rest [7]. Gallium in these two major applications is in the form of gallium arsenide (GaAs) and gallium nitride $(\mathrm{GaN})$ respectively. These applications command high quality [7], as such, impurities are relatively 


\section{International Journal of Science and Research (IJSR) \\ ISSN (Online): 2319-7064}

Index Copernicus Value (2015): 78.96 | Impact Factor (2015): 6.391

low and are likely to be from production methods used. Some reported impurities include oxygen, zinc, tellurium and sulphur [12-14] in the purity of over $99.9 \%$. Total gallium concentration in LED devices ranges from 0.001 to 0.005 $\mathrm{g} /$ unit $[1,15]$. Since demand for gallium in these applications is projected to increase as the demand for electronic devices such as smartphones, tablets, laptops and LED TVs increases then it follows that the observed proliferation of mobile phones and tablets is expected to elevate the demand for gallium to several times the current world production [3]. Production of gallium arsenide is $30 \%$ efficient and $70 \%$ is captured for recycling and the capturing is only $71 \%$ efficient. Since the current technology does not allow extraction of gallium on its own [12], therefore, decline in production of one or more host elements can seriously affect its production $[3,6,7]$. This loss, besides the loss in primary production could add more to the criticality of the element. So, one of the feasible response is to search for alternative sources from which it can be extracted. It is the opinion of this paper that the more the alternative sources from which gallium can be extracted the lesser the chance to have limitedness of its supply.

\section{Research methodology}

The expanding demand for element gallium coupled with limitedness in supply is a sufficient cause to seek for viable alternatives well before the situation is uncontrollable. Since there is enough literature in database with different alternative options, it is important to assemble and analyse information from literature that point economically viable options. A systematic search for relevant literature was done by first revisiting the production process, its sustainability and economic aspects and then options for sustainable supply. Key literatures were obtained by using selected search phrases, namely, "gallium production", "gallium recovery", and "gallium recovery from electrical and electronic wastes" in the web of science, google scholar and other subscription databases. The sources that were consulted were primarily research and review papers, books and in very few instance other sources. The information obtained from these sources were organised into the following sections; gallium production (sustainability and economic aspect of gallium production) and options to sustain gallium supply. In the first section the concentration of gallium in the common sources is presented and further discussed together with changes in production over time. Further the sustainability and the economic aspect of production are discussed in brief. In the options section two alternatives are plainly presented and discussed. Abundances of element gallium in the alternative sources relative to the already exploited sources, peculiar (non-substitutable) properties of gallium and the ease and relatively low cost of the extraction technologies so far studied were used to support the opinion that obtainment of the element from such alternative sources is a worthwhile pursuit. Although this work has not exhausted all the literatures, it has included enough fundamental literatures and contains information needed to make decision.

\section{Results and Discussion}

\subsection{The general overview of gallium production}

Gallium is listed among the critical elements because it is a dispersed trace element that is principally mined as a companion element in aluminium and zinc production besides its high demand [7,16]. Crustal concentrations of gallium in the ore of host element, ranges between 17 to some amount less than $100 \mathrm{ppm}[3,7]$. Other elements in this category include germanium, tellurium, and indium. In addition to its low concentration in the host element ore, mining efficiency of gallium in aluminium mines is only $60 \%$ [7]. Therefore, in 201 lout of 20,036 t only $12,612 \mathrm{t}$ was the maximum extractable limit from all the sources [7]. The contribution of each source is estimated to be 5439 and $711 \mathrm{t}$ from bauxite and zinc ore respectively [7]. Total gallium extraction from aluminium and zinc ore in that year (2011) was $292 \mathrm{t}$ which is only $1.38 \%$ of the total amount and approximately $5 \%$ of extractable gallium from bauxite and zinc ore combined. This indicates a huge loss of this element in primary production [3]. Gallium has unique properties that give it wide application in both electrical and electronic equipment, notably in photovoltaics and semiconductors technologies $[3,6]$.

Primary production of gallium is by co-extraction in aluminium and zinc production mainly from bauxite $(\mathrm{Al})$ and sphalerite $(\mathrm{Zn})$ ores $[3,7,16,17]$. Occurrence of gallium in these host elements ores is less than $100 \mathrm{ppm}$ [7]. Distribution of world deposits of gallium is not even, more concentration is found in certain political regions with China taking the lead by producing about $70 \%$ of $[1,3,15]$. The increase in the world population coupled with proliferation of electronic devices and shift to green energy require an assured supply of gallium. This uneven distribution may either create resource (political) monsters or make a shift to green energy in resource poor regions a failure. Therefore something must be done to ensure sustainability of this critical element.

\subsection{Sustainability aspect of gallium production}

Steady increase of demand for element gallium calls for increase in its supply. To meet this growth in demand production process is to be scrutinised to find areas that can be modified. One such area is consideration of the alternative sources that are yet to be exploited [18]. Two facts support this; (i) the already exploited sources are not meeting world demand [7] and (ii) unexploited alternative sources have more than half the total world deposit of gallium $[7,18]$. Moreover, not all what is in rock reserve is extractable; about a half of the total deposit cannot be extracted using the current technology [7]. There is a huge material loss in the whole range of gallium handling, from primary production all the way to product fabrication [3]. To have a real feeling of this, 2011 gallium flow is highlighted. Out $20036 \mathrm{t}$ of gallium in deposits, only $292 \mathrm{t}(\sim 1.4 \%)$ was extracted in that year and $86 \mathrm{t}$ was from the stockpile making a total of $378 \mathrm{t}$ global supply in that year [7]. Sources of losses included lack of Ga extraction facilities in some of the aluminium and zinc 


\section{International Journal of Science and Research (IJSR) \\ ISSN (Online): 2319-7064}

Index Copernicus Value (2015): 78.96 | Impact Factor (2015): 6.391

extraction mines and low Ga extraction efficiency 60\% [7]. The application distribution of $378 \mathrm{t}$ was such that $267.6 \mathrm{t}$ $(\sim 70 \%), 101.7 \mathrm{t}(\sim 27 \%), 5.4 \mathrm{t}(1.4 \%)$ and $(\sim 1.6 \%)$ were used for integrated circuits as (GaAs), laser diode(LD) and LED $(\mathrm{GaN})$, photodetectors $(\mathrm{GaN})$, and solar cells(CIGS) and research and development combined respectively. Production of GaAs was only $30 \%$ efficient, $70 \%$ was captured for recycling which was again $71 \%$ efficient. In production of LD and LED, and solar cells only $10 \%$ and $14.5 \%$ of $\mathrm{Ga}$ respectively was successfully embedded in products. These losses are attributed to high quality requirement of $\mathrm{Ga}$ in corresponding products. Therefore, in total, out of $378 \mathrm{t}$ only $47 \%$ was embedded in intermediate and end use products [7]. This underscores the importance of the concept of circular economy that involves recycling of waste and or rejects in form of scrap or wastewater and endof-life products to lessen these loses $[2,3,4,13,19-21,30]$. This is because unlike in primary production, recovery of $\mathrm{Ga}$ from e-waste has efficiencies of up to $>95 \%$ as shown in table 1 below.

\subsection{Economic aspect of gallium production}

Criticality of elements in most cases elevates the price of products made from them; however, for gallium this is not always the case as its specialised properties allow small incorporation to bring enough of the desired effect in the destined products $[11,15]$. However, if this continues steadily, a point will eventually be reached when such effects will no longer be avoidable. The uneven distribution of crustal reserves of this element [1,7] coupled with political greedy and market monopoly can harm both its price and supply. For example in the United States market gallium price decreased steadily from $688 \mathrm{USD} / \mathrm{kg}$ in 2011 to 362 $\mathrm{USD} / \mathrm{kg}$ in 2014 due to overproduction in China. This signifies that if efforts are properly directed in the production avenue, a significant relief in the criticality of this element is expected. With the skyrocketing demand for gallium discussed in the previous sections, short term option is vitally important and that is already an orientation in some European countries [14].

Potential sources for primary production of gallium are fly ash from coal combustion, phosphate ores, aluminous claystone, and mudstone with concentration $<100 \mathrm{ppm}$ on average [1,7,22-26]. Fly ash constitutes a single largest reservoir from which gallium can be extracted (table 1) [7]. For instance out of 12,612 t of the total extractable deposit of gallium in 2011, $6462 \mathrm{t}$ was in coal fly ash, and 6150 from bauxite and zinc ore combined [7]. Surprisingly, extraction from these sources is not implemented at least not at wider scale [7].

\subsection{Options to sustain gallium supply}

\subsubsection{Substitution by other non-critical elements}

Research has revealed that it is not feasible to extract critical elements on their own rather as companion metals (Lett et al., 2014), thus, they are always co-extracted as by-products in the extraction of their host elements ( $\mathrm{Al}$ and $\mathrm{Zn}$ ). In fact many metals that are important in modern technology are available as companion metals in various host element ores $[3,14]$. It would present a relief if these metals could be substituted by other elements that are cheap and plenty in availability. The major substitute of element gallium in photovoltaic technology is silicon in crystalline photovoltaic technology (CPT). Since silicon is cheap and plenty and that CPT have demonstrated good performance it would thus appear to be a recommendable substitute. However, when large space installations are needed, thin-film photovoltaic technology which is gallium-based outperforms the CPT [9]. Thus, even though silicon can substitute gallium in photovoltaic devices; gallium-based devices are more efficient than silicon devices [8]. This high efficiency of gallium based PV devices is possible due to the fact that they offer wide band gap energy range, high carrier mobility, and absorption coefficients, small sensitivity to ionizing radiation and use small effective mass than Silicon based PV devices $[1,15,22,23]$. For instance, while only $0.119 \mathrm{~g}$ of $\mathrm{Ga}$ is required per unit of PV cell, 226g of Si would be required for the same unit [15]. This implies that, the role of element gallium in the electrical and electronic devices is a specialised one; therefore there appears to be trade-offs between the criticality and substitutability which should be considered [12], such that neither the efficiency nor the performance of a destined product is seriously affected. There is an economic advantage as material intensity of gallium in gallium-based devices is relatively lower than its substitute [11,15]. There are initiatives to obtain semiconducting properties of gallium from iron nanoparticles [12]. This though is yet to assure a substitute for element gallium. This therefore means that, for successful substitution of gallium a number of economic challenges associated with establishing properties of a targeted substitute element should be addressed [12]. Therefore, element gallium is yet to have a perfect substitute that can have equivalent performance and or efficiency [7].

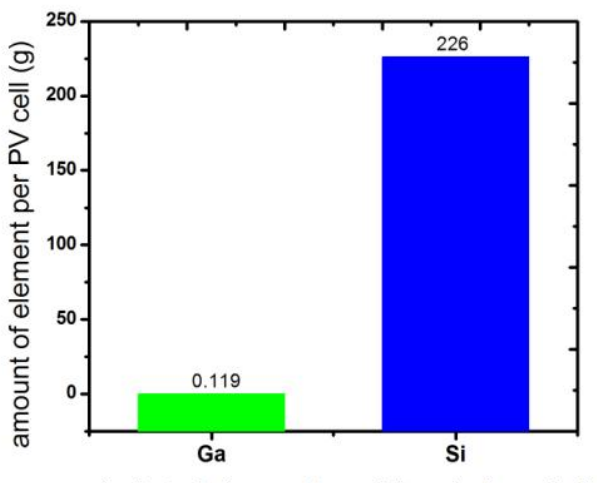

substituted element type (chemical symbol)

Figure 1: Effect of gallium substitution on amount of substitute used $[1,15,22,23]$

3.4.2 Recovery of gallium from gallium containing end oflife products wastes (electrical \& electronic waste)

Recycling of end-of-life products for recovery of gallium and other critical elements is only at its infancy in developed world with very few reported schemes like Orbite Aluminae Canadian company in Canada and another in central Europe $[7,13,27]$. This could be due to unprofitability of the exercise as the end-of-life products have not accumulated enough to be able to pay the effort worth it [21]. Material intensity in 


\section{International Journal of Science and Research (IJSR) \\ ISSN (Online): 2319-7064 \\ Index Copernicus Value (2015): 78.96 | Impact Factor (2015): 6.391}

the end-of-life products is also too low to make the recycling business attractive $[7,11]$. That is to say, the acid and or base leaching and thermal decomposition technology present are somewhat costly that their implementation seems too likely to be generating losses than profit. Therefore, the economic analysis rules that, it is unprofitable to recycle end-of-life products for gallium recovery. As presented in section 3.1 however, this reservoir is expected to grow in size with time. It is thus clear from this that sooner or later; the challenges associated with size of reservoirs will automatically be not applicable.

Alternatively, since gallium is used together with other critical and or precious metals, other options would be to coextract it together with other elements that co-occur in the destined waste. To this effect, this section gives a brief account on the common gallium bearing end-of-life devices (EOL devices) their reported gallium and other precious metals concentration co-existing with gallium in those selected EOL devices. Further, the currently recycled precious metals from identified EOL devices, recycling method used, gallium recycling methods reported, possibility of co-recycling $\mathrm{Ga}$ with other precious metals already being recycled (proposed approach) is presented.

Common EOL devices that bear element gallium include, LED notebooks, LED TVs, LCD monitors, LED monitors, and PV panels. Gallium concentrations in these devices are $0.0016,0.005,0.003,0.003$, and $0.119 \mathrm{~g} / \mathrm{unit}$ respectively [1,19,28-31]. Device parts rich in metals precious, critical, and non-precious are circuit boards.

Precious metals that are common in these EOL gallium bearing devices include gold, palladium, platinum and silver [1]. Out of these, gold is the most commonly recycled metal from electronic devices. This is attributable to its higher selling prices than other precious metals. Concentrations of gold in these devices are; LED notebooks ( $0.22 \mathrm{~g} / \mathrm{unit}), \mathrm{LED}$ TVs (0.11 g/unit), LCD monitors (0.2 g/unit), LED monitors (0.2 g/unit), and PV panels (0 g/unit) [1]. For PV panel which have no gold component, other critical and non-critical metals such as indium ( $0.119 \mathrm{~g} / \mathrm{unit})$ and copper (78 g/unit) are present [1]. It can be stated here that $\mathrm{Ga}$ can be corecycled together with gold, indium and copper from these products.

Recovery of gold from e-waste is achieved by either pyrometallurgy or hydrometallurgy [19,28,29,31-33]. In pyrometallurgy gold containing waste is thermally decomposed at $\sim 1200^{\circ} \mathrm{C}$ to release the pure gold and other oxides of metals [33]. Hydrometallurgy involves the use of chemicals to strip off gold from waste material in what is called leaching process. The commonly used leachants are cyanide, pure acids, mixed acids (aqua regia) and thiosulphate at ordinary or room temperatures [31,33]. Biosorption and vacuum metallurgy are yet other methods with least environmental harm [28,29,31,33]. Some approach combine more than one method to enhance recovery efficiency.

Studies showed that gallium can be extracted from EOL devices by such methods as pyrometallurgy and alkaline and acid baths $[1,14,15]$. $\mathrm{HCl}$ acid as leachant for example has extraction efficiency of up to $64.62 \%$ at $100^{\circ} \mathrm{C}$ and $4 \mathrm{M} \mathrm{HCl}$ concentration [14]. A combination of pyrometallurgy at $\sim 1150^{\circ} \mathrm{C}$, physical disaggregation and vacuum separation showed up to $95.67 \%$ gallium recovery efficiency from LED wastes [32].

A close eye to these methods reveals a combination of pyrometallurgy and hydrometallurgy can provide an efficient recovery method especially when gallium is to be corecovered with gold. While the first pyrometallurgy will serve the purpose of separation between gold and the rest of the metals (in their oxide form) and the hydrometallurgy will separate the gallium from the rest by acid leach followed by commercial extractant (amberlite) ([34]. Thus, those companies that recover gold from this waste by pyrometallurgy can include infrastructures that will enable the subsequent extraction of gallium in the generated wastes [35].

On the other hand, since acid leach is known to recover both gold and gallium, one option which can be used to co-recover gallium with gold in gold recycling centres is optimising conditions in acid baths. [14]. This therefore constitute alternative 2 for addressing the economic challenges behind establishment of standalone gallium recovery centres. When two or more metals are targeted in co-recovery, economic viability and sustainability of the approach is assured. Since a precious metal $(\mathrm{Au})$ recovery is already in operation insertion of facilities to include gallium as a co-recovered metal is not unachievable.

\subsubsection{Extraction from coal fly ash in energy plants}

As pointed earlier, coal fly ash constitutes the largest reservoir of gallium that has not fully been exploited. Several individual studies have pointed to this waste from energy plants as an alternative potential reservoir for element gallium [5,36-39]. However, gallium extraction from coal combustion or gasification waste is yet to be put to large scale exploitation [3,7]. The presence of gallium in coal ash is well established by different studies [36-39]. Whereas the in some coal samples the concentration of gallium is in the order of $1 \mathrm{ppm}$ [38] its concentration in fly ash is 57 times greater. In other fly ash samples the concentration of gallium is up to $230 \mathrm{ppm}$ [37]. Xiao-quan et al. [36] quantified up to $58 \mathrm{ppm}$ of gallium in the fly ash and 8 in coal samples. This then suggests that the gasification or combustion of coal serves to concentrate the $\mathrm{Ga}$ in the coal.

Gallium in fly ash occurs in the oxide and sulphide form in the oxidation state of +3 as substitutes for $\mathrm{Al}^{3+}[40,41]$. These forms are prone to acid and alkalis attack and the acid and or alkalis leach can provide the better recovery method [36-39].

The extraction methods so far tested include acid leach $(\mathrm{HCl}$ and $\mathrm{H}_{2} \mathrm{SO}_{4}$ ) [41], acid-commercial extractants leach [34] and alkali $(\mathrm{NaOH})$ leach (Font et al., 2007). Their extraction efficiencies are $60-86 \%$ for $\mathrm{NaOH}$ leach, $>55 \%$ for acid leach and commercial extractants, and $50 \%$ for acid leach. The concentration of gallium increase with decreasing particle size of fly ash while extraction efficiency increasing 


\section{International Journal of Science and Research (IJSR) \\ ISSN (Online): 2319-7064 \\ Index Copernicus Value (2015): 78.96 | Impact Factor (2015): 6.391}

with increasing concentration of acid or alkalis. It thus follows that the better places to establish these gallium extraction mines projects is the coal based energy plants not merely coal mines.

Since the methods to quantify gallium in fly ash are already known with efficiency of $>95 \%$ [36-39], it then follows that the flay ash wastes in different coal based energy plants can be characterised for possible extraction of gallium. Furthermore, the leaching agents which have shown good results are common chemicals easily available $(\mathrm{HCl}$ and $\mathrm{H}_{2} \mathrm{SO}_{4}$ ). This implies that the whole method will not be overwhelmingly costly even technologically and economically developing nations. It is also promising to note that the extraction efficiency by acid leach and commercial extractants is nearly the same as that reported in aluminium liquor process. Even though the proposed gallium mines will economically be attainable only at coal based energy plants, this added source of gallium will add to the total world production of gallium thence minimizing any chances of commodity scarcity.

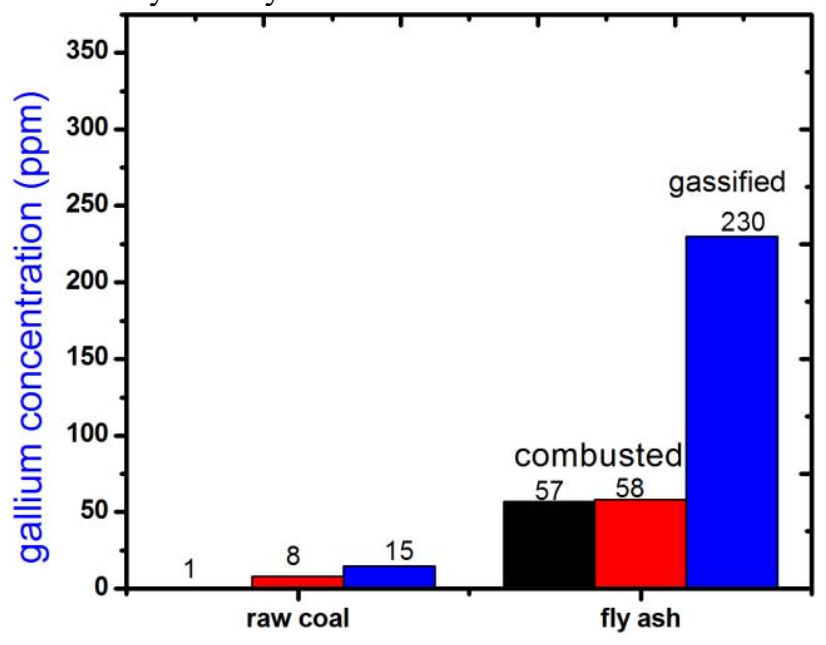

coal state

Figure 2: Effect of coal combustion/gasification on $\mathrm{Ga}$ concentration [36-39]

Table 1: The different Ga reservoirs

\begin{tabular}{|c|c|c|c|c|c|}
\hline $\begin{array}{c}\text { Resource/ } \\
\text { deposit } \\
\text { type(s) }\end{array}$ & $\begin{array}{c}\text { Exploitation } \\
\text { status }\end{array}$ & $\begin{array}{c}\text { Total } \\
\text { amount }(\mathrm{t})\end{array}$ & $\begin{array}{c}\text { Total } \\
\text { production } \\
\text { from the } \\
\text { source }(\mathrm{t})\end{array}$ & $\begin{array}{c}\text { Extraction } \\
\text { efficiency } \\
(\%)\end{array}$ & $\begin{array}{c}\text { Refere } \\
\text { nces }\end{array}$ \\
\hline bauxite & exploited & 5,439 & \multirow[t]{2}{*}{292} & \multirow[t]{2}{*}{60} & \multirow[t]{2}{*}{ [7] } \\
\hline zinc & exploited & 711 & & & \\
\hline fly ash & unexploited & 6,462 & Nil & $50-86$ & {$\left[\begin{array}{c}{[34,40,} \\
41]\end{array}\right.$} \\
\hline $\begin{array}{l}\text { End-of- } \\
\text { life } \\
\text { products }\end{array}$ & $\begin{array}{c}\text { Infant in few } \\
\text { places }\end{array}$ & $\begin{array}{c}\text { Ever } \\
\text { increasing }\end{array}$ & $\begin{array}{c}\text { Not } \\
\text { documented }\end{array}$ & $>95$ & $\begin{array}{c}{[7,13,2} \\
7]\end{array}$ \\
\hline
\end{tabular}

\section{Conclusion}

Therefore, just as gallium is co-extracted as a companion metal in primary production of aluminium and zinc, so it should be recovered from EOL devices. The metal with which gallium can be co-recovered from e-waste, gold in this case, is precious and recovery facilities are already in place.
Small concentrations of gallium in these electrical and electronic EOL products coupled with its relatively low prices command that this approach is adopted. Since recovery of primary metal, gold in this case, takes place at similar conditions as gallium, this approach is not likely to cause technical, economic and infrastructural reformations beyond accommodation in the present gold recovery facilities. Alternatively, fly ash presents a largest reservoir of gallium that has not been fully exploited. This paper then suggests that, it is now time to direct research efforts to optimising conditions for co-recovery of $\mathrm{Ga}$ with gold from electrical and electronic waste and fly ash.

\section{Acknowledgements}

The author expresses sincere appreciation for the constructive and valuable comments from Prof. Tom van Gervan of the Faculty of Engineering Science, KU Leuven, Belgium and anonymous reviewers for their insightful comments.

\section{Conflict of Interest}

The author declares no conflict of interest.

\section{References}

[1] H. Duan, J. Wang, L. Liu, Q. Huang, \& J. Li, "Rethinking China's strategic mineral policy on indium; Implication for flat screens and photovoltaic industry". Progress in Photovoltaics Research Applications. 2015.

[2] P.A.T. Lusty, \& A.G. Gunn, "Challenges to global mineral resources security and options for future supply". Geological Society, London Special Publications, 393(1), 265-276, 2015.

[3] A.N. Lovick, E. Restrepo, \& D. B. Muller, "The global anthropogenic gallium system: Determinants of demand supply and efficiency improvements". Environmental Science and Technology, 49, 5704-5712, 2015.

[4] R. Bleischwitz, "International economics of resources, productivity-relevance, measurement, empirical trends, innovations and innovation, resource policies". International Economics and Economic Policy, 7(2-3), 227-244, 2010.

[5] S. Qin, Y. Sun, Y. Li, J. Wang, C. Zhao, \& K. Gao, "Coal deposits as promising alternative sources for gallium”. Earth Science Reviews, 150, 95-101, 2015.

[6] L. Grandell, \& M. Hook, "Assessing rare earth metals availability challenges for solar energy sustainability". Sustainability, 7, 11818-11837, 2015.

[7] C. Licht, L.T. Peiro, \& G. Villaba, "Global substance flow analysis of gallium, germanium and indiumQuantification of extraction, uses, and dissipative losses within their anthropogenic cycles". Journal of Industrial Ecology, 19(5), 890-903, 2015.

[8] M. Hosenuzzaman, N.A. Rahim, J. Selvaraj, M. Hasanuzzman, A.B.M.A. Malek, \& A. Nahar, "Global prospects, policies and environmental impact of solar photovoltaic power generation". Renewable and Sustainable Energy Reviews, 41, 284-297, 2015. 


\section{International Journal of Science and Research (IJSR) \\ ISSN (Online): 2319-7064}

Index Copernicus Value (2015): 78.96 Impact Factor (2015): 6.391

[9] P. Viebahn, O. Soukup, S. Samadi, J. Teubler, K. Wiensen \& M. Ritthoff, "Assessing the need for critical minerals to shift the German energy system towards a high proportional of renewables". Renewable and sustainable energy reviews. 49, 655-671, 2015.

[10]E.G. Hertwich, T. Gibon, E.A. Bouman, A. Arvesen, S. Suh, G.A. Heath, J.D. Bergesen, A. Ramirez, M.I. Vega, \& L. Shi, "Integrated life-cycle assessment of electricity supply scenarios confirm global environmental benefit of low carbon technologies". Proceeding of National Academy of Sciences of the United States of America, 112(20). 6277-6282, 2015.

[11] M. Woodhouse, A. Goodrich, R. Margolis, T.L. James, M. Lokanc, \& R. Eggert, "Supply chain dynamics of tellurium, indium, and gallium within the context of PV manufacturing costs". IEEE Journal of Photovoltaics, 3(2), 833-837, 2013.

[12]E. Letts, T. Hashimoto, S. Hoff, D. Key, K. Male \& M. Michaels, "Development of $\mathrm{GaN}$ wafers via the ammonothermal method". Journal of Crystal Growth, 403, 3-6, 2014.

[13]A.J. Ritenour, J.W. Boucher, R. DeLancey, A.L. Greenaway, S. Aloni, \& S.W. Boettcher, "Doping and electronic properties of GaAs grown by close-spaced vapor transport from powder sources for scalable III-V photovoltaics", Energy \& Environmental Science, 8(1), 278-285, 2015.

[14]B. Swain, C. Mishra, L. Kang, K.S. Park, C.G. Lee, \& H.S. Hong, "Recycling process for recovery of gallium from GaN an e-waste of LED industry through ball milling, annealing and leaching", Environmental research, 138, 401-408, 2015.

[15]F. Cucchiella, I. D'Adamo, S.C.L. Koh \& P. Rosa, "Recycling of WEEEs: An economic assessment of present and future e-waste streams", Renewable and Sustainable Energy Reviews, 51, 263-272, 2015.

[16] S. Qin, Y. Sun, Y. Li, J. Wang, C. Zhao, \& K. Gao, "Coal deposits as promising alternative sources for gallium”, Earth Science Reviews, 150, 95-101, 2015.

[17]F.M. Meyer, "Availability of bauxite reserves", Natural Resources Research, 13(3), 161-172, 2004.

[18] M.Frenzel, M. Ketris, T. Seifert, \& J. Gutzmer, "On the current and future availability of gallium", Resources Policy, 47, 38-50, 2016.

[19] K.W. Torrance, H.E. Keenan, A.S. Hursthouse, \& D. Stirling, "Measurement of arsenic and gallium of gallium arsenide semiconductor waste streams by ICP-MS". Journal of Environmental Science and Health Part A, 45, 471-475, 2010.

[20] T. Zimmermann \& S. Goßling-Reisemann, "Recycling potential of critical metals-Analysing secondary flows from selected applications", Resources, 3, 291-318, 2014.

[21] N.T. Nassar, T.E. Gaedel, \& E.M. Herper "Byproduct metals are technologically essential but have problematic supply", Science Advances, 1(3), e1400180, 2015.

[22] J. Wu, W. Walukiewicz, K.M. Yu, J.W. Ager, E.E. Haller, H. Lu, \& W.J. Schaff, "Small Band Gap Bowing in In1ÀxGaxN alloys", Applied Physics Letters, 80, 4741-4743, 2002.

[23] J. Wu, W. Walukiewicz, K.M. Yu, W. Shan, J.W. Ager, E.E. Haller, H. Lu, W.J. Schaff, W.K. Metzger, \& S.
Kurtz, "Superior Radiation Resistance of In1-xGaxN Alloys: Full-Solar-Spectrum Photovoltaic Material System", Journal of Applied Physics, 94, 6477-6482, 2003.

[24] O. Jani, I. Ferguson, C. Honsberg, \& S. Kurtz, "Design and Characterization of GaN/InGaN Solar Cells", Applied Physics Letters, 91, 132117-132119, 2007.

[25] O. Laboutin, Y. Cao, W. Johnson, R. Wang, G. Li, D. Jena, \& H. Xing, "InGaN Channel High Electron Mobility Transistor Structures Grown by Metal Organic Chemical Vapor Deposition", Applied Physics Letters, 100, 121909-121911, 2012.

[26]E.I. Gkanas, Y.L. Barkouros, \& S.S. Makridis, "Sustitutionability of the critical raw materials in energy application: A short review and perspective", Material Science and Engineering with Advanced Research, 1(3), $1-9,2015$.

[27] R.R.Moskalyk "Gallium: the backbone of the electronics industry”, Minerals Engineering, 16(10), 921-929, 2003.

[28] J.A. Sturgill, J.T. Swartzbaugh, \& P.M. Randal, "Pollution prevention in the semiconductor industry through recovery and recycling of gallium and arsenic from GaAs polishing wastes". Clean Products and Processes, 2, 18-27, 2000.

[29]L. Zhan, \& Z. Xu, "State-of-the-Art of Recycling EWastes by Vacuum Metallurgy Separation", Environmental science \& technology, 48(24), 1409214102, 2014.

[30]F. Cucchiella, I. D’Adamo, P. Rosa, "End-of-life used photovoltaic modules: A financial analysis", Renewable and Sustainable Reviews, 47, 552-561, 2015.

[31] L.N. Côrtes, E.H. Tanabe, D.A. Bertuol, \& G. Dotto "Biosorption of gold from computer microprocessor leachate solutions using chitin", Waste Management, 45, 272-279, 2015.

[32] J. Li, P. Shrivastava, Z. Gao \& H.C. Zhang, "Printed circuit board recycling: a state-of-the-art survey", Electronics Packaging Manufacturing, IEEE Transactions on, 27(1), 33-42, 2004.

[33] A. Khaliq, M.A. Rhamdhani, G. Brooks, \& S. Masood, "Metal extraction processes for electronic waste and existing industrial routes: a review and Australian perspective", Resources, 3(1), 152-179, 2014.

[34] B. Gutiérrez, C. Pazos, \& J. Coca, "Recovery of gallium from coal fly ash by a dual reactive extraction process", Waste management \& research, 15(4), 371-382, 1997.

[35]E.Y. Sum "The recovery of metals from electronic scrap", JOM, 43(4), 53-61, 1991.

[36] S. Xiao-quan, W. Wen, \& W. Bei, "Determination of gallium in coal and coal fly ash by electrothermal atomic absorption spectrometry using slurry sampling and nickel chemical modification", Journal of Analytical Atomic Spectrometry, 7(5), 761-764, 1992.

[37]I. Tsuboi, S. Kasai, E. Kunugita \& I. Komasawa, "Recovery of gallium and vanadium from coal fly ash", Journal of chemical engineering of Japan, 24(1), 15-20, 1991.

[38] X. Shan, Z. Yuan, \& Z. Ni, "Determination of gallium in sediment, coal, coal fly ash, and botanical samples by graphite furnace atomic absorption spectrometry using nickel matrix modification", Analytical Chemistry, 57(4), 857-861, 1985.

\section{Volume 6 Issue 1, January 2017


[39] S. Dai, L. Zhao, S. Peng, C.L. Chou, X. Wang, Y. Zhang, \& Y. Sun, "Abundances and distribution of minerals and elements in high-alumina coal fly ash from the Jungar Power Plant, Inner Mongolia, China", International Journal of Coal Geology, 81(4), 320-332, 2010.

[40]Z. Fang, \& H.D. Gesser, "Recovery of gallium from coal fly ash", Hydrometallurgy, 41(2), 187-200, 1996.

[41] O. Font, X. Querol, R. Juan, R. Casado, C. Ruiz, A. López-Soler, \& F.G. Peña, "Recovery of gallium and vanadium from gasification fly ash", Journal of hazardous materials, 139(3), 413-423, 2007.

\section{Author Profile}

Hezron Mwakabona received his B.S. and M.S. degrees in Chemistry and Environmental Science and Engineering from University of Dar es Salaam in 2010 and Nelson Mandela African Institution of Science and Technology 2014 respectively in Tanzania. From 2011 up to date he works as a faculty member at the Faculty of Science, Sokoine University of Agriculture, Morogoro, Tanzania. 